Best Pract Res Clin Gastroenterol. 2016 April ; 30(2): 145-159. doi:10.1016/j.bpg.2016.02.007.

\title{
Physiology of Intestinal Absorption and Secretion
}

\author{
Pawel R. Kiela, DVM, PhDa,b and Fayez K. Ghishan, MD ${ }^{a}{ }^{*}$ \\ aDepartment of Pediatrics, Steele Children's Research Center, University of Arizona Health \\ Sciences Center, 1501 N. Campbell Ave., Tucson, AZ 85724, USA \\ bDepartment of Immunobiology, University of Arizona Health Sciences Center, 1656 E. Mabel St., \\ Tucson, AZ 85724, USA
}

\begin{abstract}
Virtually all nutrients from the diet are absorbed into blood across the highly polarized epithelial cell layer forming the small and large intestinal mucosa. Anatomical, histological, and functional specializations along the gastrointestinal tract are responsible for the effective and regulated nutrient transport via both passive and active mechanisms. In this chapter, we summarize the current state of knowledge regarding the mechanism of intestinal absorption of key nutrients such as sodium, anions (chloride, sulfate, oxalate), carbohydrates, amino acids and peptides, lipids, lipidand water-soluble vitamins, as well as the major minerals and micronutrients. This outline, including the molecular identity, specificity, and coordinated activities of key transport proteins and genes involved, serves as the background for the following chapters focused on the pathophysiology of acquired and congenital intestinal malabsorption, as well as clinical tools to test and treat malabsorptive symptoms.
\end{abstract}

\section{Keywords}

Epithelial transport; Sodium; Chloride; Short chain fatty acids; Sulfate; Oxalate; Carbohydrates; Amino acids; Lipids; vitamins; Minerals; Micronutrients

\section{Introduction}

This chapter emphasizes the physiology of intestinal absorption. The transport protein responsible for absorptive function of the gastrointestinal tract resides in the apical side of the villous structure, which is involved in facilitating the transport of nutrients across the length of the small intestine. Recent advances in molecular cloning have led to further understanding of these transport proteins and how they are altered in the settings of health and disease states. The chapter will also discuss the intestinal transport of ions, short chain fatty acids, sulfate, oxalate; as well as major nutrients such as carbohydrates, proteins, and fats. The chapter concludes with a discussion of the absorption of water-soluble vitamins, fat-soluble vitamins, minerals, and micro-nutrients.

"Corresponding author. fghishan@peds.arizona.edu (F.K. Ghishan). . pkiela@peds.arizona.edu (P.R. Kiela)

Conflict of interest

No conflict of interest has been declared by the authors. 


\section{Functional anatomy of the GI tract}

The GI tract evolved to facilitate the transport of nutrients throughout its length. The small intestine measures approximately $6 \mathrm{~m}$ in length and $2.5-3.0 \mathrm{~cm}$ in diameter. The colon measures approximately $1.5 \mathrm{~m}$ in length with a diameter of $6-7.5 \mathrm{~cm}$. The surface area of the small intestine is significantly enhanced by the presence of villi and microvilli, which increase the intestinal surface area by 30-600 fold, respectively. Villi are approximately $0.5-$ $1.6 \mathrm{~mm}$ in length and are covered with columnar epithelial cells at the tip. These are mostly absorptive cells, whereas crypt cells are generally regarded as secretory. Most of the nutrient transport occurs in the small intestine, whereas the colon is primarily responsible for water and electrolyte transport. The GI tract is responsible for handling approximately $8-10 \mathrm{~L}$ of fluid containing approximately $800 \mathrm{mmol}$ of sodium $\left(\mathrm{Na}^{+}\right), 700 \mathrm{mmol}$ of chloride $\left(\mathrm{Cl}^{-}\right)$, and $100 \mathrm{mmol}$ of potassium $\left(\mathrm{K}^{+}\right)$that passes through the intestinal lumen every day. The bulk of the transport of these fluids and electrolytes occurs through the small intestine, leaving approximately $1.5 \mathrm{~L}$ for the colon to absorb and leaving approximately $100 \mathrm{~mL}$ that is lost through the stools every day. The mechanisms responsible for the solute transport across the GI tract are secondary to several transport proteins located at the brush border membranes of the small and large intestine. The net fluid movement across the gastrointestinal epithelium is primarily the result of active transport of $\mathrm{Na}^{+}, \mathrm{Cl}^{-}$, and $\mathrm{HCO}_{3}{ }^{-}$, among others.

\section{Intestinal $\mathrm{Na}^{+}$absorption}

Three mechanisms contribute to the apical $\mathrm{Na}^{+}$transport in the small intestine: (a) nutrientcoupled $\mathrm{Na}^{+}$absorption mediated by several families of $\mathrm{Na}^{+}$-dependent nutrient transporters such as sugar or amino acid transporters discussed separately in this chapter, $(b)$ electroneutral $\mathrm{NaCl}$ absorption mediated primarily via the $\mathrm{Na}^{+} / \mathrm{H}^{+}$exchange mechanism [1], and (c) colon-predominant electrogenic $\mathrm{Na}^{+}$absorption by the epithelial $\mathrm{Na}^{+}$channels $(\mathrm{ENaC})$ [2]. Electroneutral $\mathrm{NaCl}$ absorption is attributed to members of the SLC9 family of $\mathrm{Na}^{+} / \mathrm{H}^{+}$exchangers. Three NHE isoforms have been identified on the enterocyte apical membrane: NHE2, NHE3, and NHE8 [3-5]. Of the three, NHE3 contributes most significantly to the intestinal $\mathrm{Na}^{+}$and water absorption. Missense mutations in SCL9A3 gene coding for NHE3 has been shown recently to be associated with congenital sodium diarrhea (CSD) [6]. Reduced expression and mistargeting of NHE3 protein in the enterocytes is also believed to be partially responsible for diarrhea in patients with microvillous inclusion disease, a rare genetic disorder associated with mutations in Myo5B or Syntaxin three. During intestinal inflammation, inhibition of NHE3-mediated $\mathrm{Na}^{+} / \mathrm{H}^{+}$ exchange has been postulated to lead to gut microbial dysbiosis, epithelial barrier defect, and exacerbated inflammatory response. There are scenarios, however, when NHE3 inhibition may be clinically beneficial. A recent study with a novel, poorly bioavailable, orally administered NHE3 inhibitor, tenapanor, showed that reduction of NHE3-mediated intestinal $\mathrm{Na}^{+}$absorption was beneficial in a rat model of chronic kidney disease, in which it reduced extracellular fluid volume, left ventricular hypertrophy, albuminuria, and blood pressure [7].

In the colon, particularly in the ascending segment, a substantial fraction of the net $\mathrm{Na}^{+}$ absorption is also mediated by electroneutral $\mathrm{NaCl}$ transport. This process is a reflection of dual $\mathrm{Na}^{+} / \mathrm{H}^{+}-\mathrm{Cl}^{-} / \mathrm{HCO}_{3}{ }^{-}$exchanges [the latter mechanism mediated by PAT1 (SLC26A6) 
and downregulated in adenoma (DRA; SLC26A3)] operating in parallel in the apical membrane. The same three major $\mathrm{Na}^{+} / \mathrm{H}^{+}$exchangers are expressed on the apical surface of colonocytes as in the small intestine. Electrogenic $\mathrm{Na}^{+}$absorption - predominant in the descending colon, sigmoid and rectum - is most commonly attributed to the activity of mineralocorticoid-regulated apical epithelial sodium channels (ENaC). This mechanism may have limited contribution to an ileal $\mathrm{Na}^{+}$transport, particularly as an adaptive response after proctocolectomy. It is mediated by apical $\mathrm{Na}^{+}$channels, which are composed of three subunits ( $(\mathrm{a}-, \beta$ - and $\gamma$-hENaC). One of the key functional characteristics of $\mathrm{ENaC}$ is its exquisite sensitivity to inhibitory effects of a pyrazine diuretic, amiloride, and stimulation by a mineralocorticoid hormone, aldosterone. Electrogenic but amiloride-insensitive $\mathrm{Na}^{+}$ absorption has also been described in the proximal colon. Although the physiological mechanism for this transport is not clearly defined, it may be related to the function of $\mathrm{Na}^{+} / \mathrm{HCO}_{3}$ cotransporters (NBC), particularly mediated by the $\mathrm{NBCe} 1 \mathrm{~B} / \mathrm{C}$ carrier.

\section{Intestinal anion absorption}

\section{Chloride absorption}

Efficiently chloride absorption in the gut results in normal stool concentration of 10-15 mmoles/L. In the states of malabsorption, such as congenital $\mathrm{Cl}^{-}$diarrhea, it can exceed 90 mmoles/L. Physiologically, $\mathrm{Cl}^{-}$is absorbed from the intestinal lumen via three distinct mechanisms: (a) paracellular (passive) pathway; (b) electroneutral pathways which involves coupled $\mathrm{Na}^{+} / \mathrm{H}^{+}$and $\mathrm{Cl}^{-} / \mathrm{HCO}_{3}{ }^{-}$exchange; and (c) $\mathrm{HCO}_{3}{ }^{-}$-dependent $\mathrm{Cl}^{-}$absorption. Passive pathway is predominant in the small intestinal epithelium and depends on the transmural potential difference and downhill $\mathrm{Cl}^{-}$gradient. The second, electroneutral exchange pathway is the main route of $\mathrm{Cl}^{-}$absorption in the ileum and colon. The coupling of $\mathrm{Na}^{+} / \mathrm{H}^{+}$and $\mathrm{Cl}^{-} / \mathrm{HCO}_{3}{ }^{-}$exchange is the result of $\mathrm{H}^{+}$efflux mediated by apical NHE isoforms (mostly NHE3). NHE-driven transient alkalinization of the cytoplasm activates the $\mathrm{Cl}^{-} / \mathrm{HCO}_{3}{ }^{-}$exchanger(s), with carbonic anhydrase being the main producer of $\mathrm{H}^{+}$and $\mathrm{HCO}_{3}{ }^{-}$. The net result is $\mathrm{Na}^{+}$and $\mathrm{Cl}^{-}$absorption in exchange for $\mathrm{H}^{+}$and $\mathrm{HCO}_{3}{ }^{-}$exit. Anion exchangers (AEs) involved in the electroneutral exchange pathway belong to the SLC26 "sulfate permease" transporter family. The DRA/CLD exchanger (SLC26A3) gene is expressed throughout the GI tract (colon predominant) and mutations in this gene underlie congenital chloride diarrhea [8]. PAT1 (SLC26A6), and specifically its splice variant SLC26A6a, is expressed on the enterocyte apical membrane in the human small intestine and colon, but with higher levels in the duodenum though ileum. PAT1 is a particularly versatile $\mathrm{AE}$, capable of several exchange modes: $\mathrm{Cl}^{-}$/oxalate, $\mathrm{SO}_{4}{ }^{2-}$ /oxalate, $\mathrm{SO}_{4}{ }^{2-} / \mathrm{Cl}-$, $\mathrm{Cl}^{-} /$formate, and $\mathrm{Cl}^{-} / \mathrm{OH}^{-}[9]$.

Several members of a heterogenous SLC4 family of AEs also contribute to the intestinal $\mathrm{Cl}^{-}$ absorption [10]. In humans, AE4 (SLC4A9) is expressed on the apical membrane of the enterocytes, while AE2 and AE3 (SLC4A2 and $S L C 4 A 3$, respectively) represent AEs which are responsible for entry of $\mathrm{HCO}_{3}{ }^{-}$into the cell for subsequent secretion. 


\section{Short chain fatty acid (SCFA) absorption}

SCFAs produced by the bacterial fermentation of carbohydrate and fiber are the major regulators of colonic sodium transport (by enhancing $\mathrm{Na}^{+} / \mathrm{H}^{+}$exchange), are the preferred energy source for the colonic epithelium, inhibit carcinogenesis, exhibit anti-inflammatory effects, modulate oxidative stress, enhance epithelial barrier function, and modulate gene transcription via inhibition of histone deacetylase (HDAC) activity [11]. Acetate, propionate, and butyrate account for approximately $95 \%$ of colonic SCFA contents, and butyrate alone has been estimated to provide $60 \%-70 \%$ of the colonocyte's energy needs. A specific carrier protein involved in this process was identified as the monocarboxylate transporter 1 (MCT1; SLC5A8), which functions as an $\mathrm{H}^{+}$-coupled electroneutral transporter [12,13]. Impaired MCT1 function as well as intracellular oxidation of butyrate has been postulated to contribute to the chronicity of IBD. MCT4 isoform $(S L C 16 A 3)$ is thought to be the main basolateral SCFA transporter in the colon, though its expression and activity of MCT4 in IBD has not been investigated.

\section{Sulfate $\left(\mathrm{SO}_{4}{ }^{2-}\right)$ absorption}

The inorganic anion sulfate $\left(\mathrm{SO}_{4}{ }^{2-}\right)$ is required for many physiological processes as well as for the maintenance of structure and function of macromolecules. Inadequate supply of sulfate inhibits detoxification, increases susceptibility to xenobiotics and alters metabolism and activities of a variety of endogenous compounds such as hormones, neurotransmitters, and proteoglycans. In the mammalian gut, $\mathrm{SO}_{4}{ }^{2--}$ is transported via two mechanisms: $\mathrm{Na}^{+}-$ dependent electrogenic $\mathrm{pH}$-insensitive high-affinity transport mediated by $\mathrm{NaS} 1$ ( $S L C 13 A 1$ ), and by $\mathrm{Na}^{+}$-independent transport mediated by Sat1 (SLC26A1; electroneutral sulfate/oxalate, sulfate/bicarbonate, or oxalate/bicarbonate anion exchange) and by DTDST (SLC26A2) [14]. Other anion transporters, such as PAT1 (SLC26A6) as well as DRA (SLC26A3), are also capable of sulfate transport and likely contribute to intestinal $\mathrm{SO}_{4}{ }^{2-}$ absorption. In humans, $\mathrm{NaS} 1$ expression is restricted to the kidneys, and is believed to play a negligible role in the intestinal $\mathrm{SO}_{4}{ }^{2-}$ absorption, which is dominated by $\mathrm{Na}^{+}$-independent mechanisms.

\section{Oxalate absorption and secretion}

Oxalate is derived mostly from plants such as beets, spinach, rhubarb, strawberries, nuts, chocolate, tea, wheat bran, and most dry beans excluding lima and green beans. It is also derived from endogenous sources as an end product of metabolism. Oxalate is absorbed in the gut passively, as well as via carrier-mediated mechanisms [15]. Passive modes include both paracellular permeability, as well as non-mediated non-ionic diffusion if the luminal $\mathrm{pH}$ is sufficiently low to fully protonate the anion. Several SLC26 family members of anion exchangers are expressed in the gut and can utilize oxalate as a substrate. The SLC26A3 gene product known as Down Regulated in Adenoma (DRA), is expressed in the human duodenum, ileum, caecum, and distal colon, and was postulated to transport oxalate in those tissues. Other SLC26 transporters, such as SLC26A1 (SAT1), SLC26A2 (DTDST), and $S L C 26 A 7$ (SUT2) also show the capacity to transport oxalate. PAT1 (SLC26A6) is responsible for cellular efflux and intestinal oxalate secretion. Intestinal oxalate absorption is 
regulated by a number of factors such as angiotensin II, which increases colonic oxalate secretion.

The clinical importance of intestinal oxalate absorption is related to its enhanced transport in the setting of intestinal inflammation and/or resection of the ileum which leads to increased influx of bile acids into the colon, stimulation of oxalate absorption, hyperoxaluria and increased risk of nephrolithiasis. Fat malabsorption increases the intestinal absorption of oxalate due to increased intestinal permeability to oxalate and formation of complexes with calcium and fatty acid. This mechanism is likely responsible for hyperoxaluria after partial gastrectomy, bariatric surgery, jejunoileal bypass, and in inflammatory bowel disease.

\section{Sugar transport across the GI tract}

The majority of consumed carbohydrates are derived from sugars and starches. Sugars include monosaccharides (e.g. glucose, galactose and fructose) and disaccharides (eg. lactose, sucrose, maltose and trehalose). Starches are the storage carbohydrates of plants and consist mainly of sugars linked together. Lactose and sucrose are hydrolyzed to monosaccharides via lactase and sucrase, respectively. Salivary and pancreatic amylase are responsible for the initial breaking down of starches, which are then followed by further digestion by mucosal enzymes (eg. amylase, sucrase and isomaltase) which are responsible for the final digestion to glucose.

The SGLT1 transporter drives the transport of glucose and galactose in the intestine. It is expressed on the brush border membrane of the enterocytes in the upper third of the small intestinal villi, and it is currently accepted that it is responsible for $\mathrm{Na}^{+}$-dependent sugar transport, which drives the uphill transport of glucose and galactose from the lumen of the gut into the enterocyte [16]. The $\mathrm{Na}^{+}$electrochemical gradient across the brush border membrane is the main driving force. The $\mathrm{Na}^{+}$gradient is maintained through the basolateral $\mathrm{Na}^{+} / \mathrm{K}^{+}$ATPase pump. It is believed that two $\mathrm{Na}^{+}$ions accompany each sugar molecule transported into the cells. SGLT1 uses a $\mathrm{Na}^{+}$gradient to transport $\mathrm{Na}^{+}$and glucose at a 2:1 ratio against a glucose gradient. In each cycle, each sugar molecule is co-transported with $\mathrm{Na}^{+}$across the cell, which is accompanied by 260 water molecules. This mechanism was calculated to account for 5 liters of water absorption per day in the human intestine and formed the molecular basis of oral rehydration therapy aimed to control mortality associated with cholera and diarrheal diseases [17]. The World Health Organization's reduced osmolarity solution is composed of the following in mmol/L: $\mathrm{Na}^{+} 75, \mathrm{Cl}^{-} 65$, glucose 75 , $\mathrm{K}^{+} 20$ and citrate 10 ; with a total osmolarity of $245 \mathrm{mOsm} / \mathrm{L}$. Oral rehydration therapy was hailed as "potentially the most important medical advance" in the 20th century [18].

Fructose is transported across the brush border membrane by a facilitated diffusion process via GLUT5 - also a member of the GLUT family of transporters [19]. Fructose is transported by GLUT2 across the basolateral membrane (BLM) of the enterocyte. Fructose malabsorption is rare. Its diagnosis depends on the clinical presentation, the presence of reducing substances in the stool, and breath hydrogen testing. However, the isolated fructose malabsorption has to be differentiated from a deficiency of the aldolase B enzyme - which leads to fructose intolerance caused by a mutation in $A L D O B$ gene. 


\section{Amino acids and peptide absorption}

The daily intake of protein in the western diet averages $100 \mathrm{~g}$ per day with an additional $35 \mathrm{~g}$ contributed by salivary and GI secretions. Low $\mathrm{pH}$ in the stomach activates pepsinogen to pepsin. Pepsin cleaves peptide bonds at the aromatic amino acids, and results in a mixture of intermediate protein moieties, peptides, and amino acids. These are then delivered to the duodenum, where pancreatic proenzymes (trypsinogen, chymotrypsinogen, proelastase, and procarboxypeptidase) become activated by mucosal enterokinase and further breakdown these products into amino acids, dipeptides and tripeptides. The activity of brush border dipeptidases continues to liberate amino acids. However, dipeptides and tripeptides can also enter the enterocyte and then get hydrolyzed by the cytoplasmic peptidases to release amino acids, which then are transported across the BLM of the enterocytes.

\section{Apical Amino Acid Transport Systems}

Amino acid transport is complex and there are a number of systems responsible for their uptake across the brush border membrane. They vary in solute specificity, $\mathrm{Na}^{+}, \mathrm{Cl}^{-}-\mathrm{H}_{-}^{+}$, or $\mathrm{K}^{+}$- dependency, and may represent an electroneutral or electrogenic transport process. A summary of amino acid transporters expressed in the human gut is shown in Table 1.

\section{Peptide transport}

Dipeptides and tripeptides are very efficiently absorbed in the small intestine. The process is indirectly $\mathrm{Na}^{+}$-dependent, in that $\mathrm{Na}^{+}$is necessary for the activity of $\mathrm{Na}^{+} / \mathrm{H}^{+}$exchanger 3 (NHE3) to generate a proton gradient for $\mathrm{H}^{+} /$peptide co-transport. Thus the two transport processes are functionally coupled. Peptides of four or more amino acids in length are poorly absorbed in a non-carrier-dependent mechanism. The carrier responsible for the intestinal uptake of peptides is known as the peptide transporter 1 (PEPT1). It is encoded by the SLC15A1 gene, and is expressed in the intestinal and, to lesser extent, renal epithelia. PEPT1 is expressed throughout the small intestine and with its high capacity for transport, very little of the dietary peptides escape the terminal ileum. It's expression in the colon is somewhat controversial, though the currently dominant view is that PEPT1 is not expressed in the colon except under certain conditions such as inflammatory bowel disease; and likely as a compensatory response - in short bowel syndrome (SBS). This observation suggests that nutritional formulas containing peptides can be used in clinical conditions where the transport system is expressed. In summary, proteins in the diet and in GI secretions are hydrolyzed initially by gastric pepsin and hydrochloric acid, then by pancreatic proteases and peptidases in the small bowel and cytoplasmic domain of the enterocyte. Therefore, $90 \%$ of absorbed dietary proteins is represented in the circulation by amino acids and $10 \%$ as dipeptides and tripeptides.

\section{Basolateral exit of amino acids}

Amino acids exit through the BLM of the enterocyte via at least six amino acid transporters. However, depending on the luminal amino acid concentration and cellular demand and on the electrogenic driving forces, these carriers may work in either direction. They form six transport systems: System A $-\mathrm{Na}^{+}$dependent transport of all neutral amino acids and imino acids (SNAT2 carrier encoded by SLC8A2); GLYT1 system $-\mathrm{Na}^{+}$and $\mathrm{Cl}^{-}$coupled 
transport of glycine (GLYT1 encoded by SLC6A9). Although bi-directional, GLYT1 primarily transports glycine into the enterocyte, e.g. for glutathione synthesis; $\mathrm{y}^{+}-\mathrm{Na}^{+}$ independent transport of cationic amino acids (lysine, arginine, ornithine) (CAT1 encoded by SLC7A1); System $\mathrm{L}-$ major $\mathrm{Na}^{+}$-independent transport system for neutral amino acids (excluding imino acids). This transport is mediated primarily by LAT2, encoded SLC7A8, which heterodimerizes with CD98, also known as heavy chain associated with the 4F2 antigen, or 4F2hc; System $\mathrm{y}^{+} \mathrm{L}$ - although not directly $\mathrm{Na}^{+}$-dependent, forms an obligatory exchange system whereby cellular cationic amino acid is exchanged for the $\mathrm{Na}^{+}$-coupled entry of a neutral amino acid from the blood. System $\mathrm{y}^{+} \mathrm{L}$ is mediated by two carriers, $\mathrm{y}^{+}$LAT1 and $\mathrm{y}^{+} \mathrm{LAT} 2$, encoded by $S L C 7 A 7$ and $S L C 7 A 6$, respectively. Similarly to system $\mathrm{L}, \mathrm{y}^{+} \mathrm{LAT} 1$ and $\mathrm{y}^{+} \mathrm{LAT} 2$ proteins heterodimerize with 4F2hc. Lastly, system Asc $-\mathrm{Na}^{+}-$ independent transport of short chain amino acids (e.g. glycine, alanine, serine, cysteine, or threonine) - is primarily mediated by the $\mathrm{ASC} 1 / 4 \mathrm{~F} 2 \mathrm{hc}$ heterodimer, which also functions as a basolateral amino acid exchanger.

\section{Lipid Absorption}

The fat digestion process starts in the mouth with lingual lipase and continues in the stomach with the addition of gastric lipase produced by chief cells. However, the majority of fat digestion occurs in the duodenum by pancreatic lipase and colipase, with the assistance of emulsifying bile acids. The monoglycerides and long chain fatty acids resulting from lipolysis along with phospholipids, cholesterol, and fat-soluble vitamins, form micelles with bile salts. The components of the micelles are then transferred into the enterocytes where long chain fatty acids and monoglycerides are re-esterified into triglycerides and subsequently combined with protein, phospholipid and cholesterol to form chylomicrons. Following this, the chylomicrons enter the intestinal lymphatics through the thoracic duct and, finally, into the peripheral circulation. Medium chain fatty acids can be absorbed into the enterocytes without being hydrolyzed. They are transported directly into the portal vein. This particular property of medium chain triglycerides makes them particularly useful in the treatment of individuals with fat malabsorption disorders such as pancreatic insufficiency, cirrhosis, and intestinal lymphangiectasia. Two transport proteins (CD36 and LFABP) appear to be involved with fatty acid entry into the enterocyte and its intracellular movement, respectively. Cholesterol transport occurs mainly through Niemann-Pick C1 like-1 (NPC1L1). This transporter is a target of Ezetimibe (Zetia or Ezetrol), an approved drug for preventing cholesterol absorption. Two ATP-binding cassette proteins (ABCG5 and ABCG8) are responsible for cholesterol efflux from enterocytes into the lumen.

\section{Water Soluble Vitamins}

Water-soluble vitamins are essential for normal growth and development as they are involved in many metabolic processes. Humans cannot synthesize many of these vitamins and, therefore, have to rely heavily on their exogenous intake [20].

\section{Vitamin C}

Humans cannot synthesize Vitamin C. Its intestinal transport occurs via a carrier-mediated $\mathrm{Na}^{+}$dependent mechanism localized at the brush border membrane. There are two known 
$\mathrm{Na}^{+}$-dependent carriers in humans: vitamin C transporter-1 (SVCT1), and SVCT2, products of the $S L C 23 A 1$, and $S L C 23 A 2$ genes, respectively. Nutritional deficiency of vitamin C results in scurvy. Major sources of vitamin $\mathrm{C}$ include citrus fruits, tomatoes, cantaloupes and strawberries.

\section{Biotin (vitamin $\mathrm{H}$ or $\mathrm{B}_{7}$ )}

The human intestine is exposed to two sources of biotin - dietary and bacterial. Biotin is absorbed via a carrier-mediated $\mathrm{Na}^{+}$-dependent process. The intestinal sodium-dependent multivitamin transporter (SMVT) encoded by the SLC5A6 gene, is responsible for biotin uptake throughout the intestinal tract. Nutritional biotin deficiency results in seborrheic dermatitis, anorexia, alopecia, myalgia and paresthesia. Excellent food sources include liver, egg yolks, soybeans, milk and meat.

\section{Cobalamin $\left(\mathrm{B}_{12}\right)$}

Cobalamin is obtained from foods of animal origin and from the colonic microbiota. Dietary cobalamin, once liberated from the animal protein, binds in the stomach to the protein haptocorrin (transcobalamin-1; TC1). Cobalamin is released from this complex in the small intestine by trypsin, after which, it binds to the gastric intrinsic factor (GIF). The $\mathrm{B}_{12} / \mathrm{GIF}$ complex binds to the multi-ligand heterodimeric receptor, cubam, composed of amnionless (AMN) and cubilin (CUBL) and located at the apical membrane of the ileal enterocytes. Following internalization, this complex goes to the endosomes where cubam is recycled back to the apical membrane and the $\mathrm{B}_{12} / \mathrm{GIF}$ complex moves to the lysosome where the IF is degraded. The released cobalamin is transported out and exported at the BLM by the multi-drug resistant associated protein-1 (MRP1). Systemically, transcobalamin carries cobalamin for utilization and storage. The major disorder associated with cobalamin deficiency or malabsorption is megaloblastic anemia. Similarly, lack of GIF due to atrophic gastritis results in megaloblastic anemia. There are also relatively rare inherited defects in intestinal absorption of cobalamin (e.g. due to mutations in the $G I F, A M N$, or $C U B L$ genes). Dietary sources of cobalamin include animal foods such as meats, fish, poultry and eggs.

\section{Folic acid (vitamin $\mathrm{M}$ or $\mathrm{B}_{9}$ )}

In addition to dietary sources, folate is also synthesized by the gut microbiota. Dietary folate exists in monoglutamate and polyglutamate forms. The enzyme, folate hydrolase, is responsible for releasing folate from its conjugated polyglutamate form in the upper small intestine. There are three carriers specific for folate - the reduced folate carrier (FOLT; product of the $S L C 19 A 1$ gene), the proton-coupled folate transporter (PCFT/HCP1; product of the $S L C 46 A 1$ gene), and the GPI-anchored folate receptor FOLR1. Folate deficiency occurs secondary to a number of causes including chronic alcohol use, intestinal disorders such as celiac disease and tropical sprue, and longtime use of sulfasalazine. Dietary sources of folate include green vegetables, liver, fruits such as oranges and cantaloupes, fortified breads and cereals. 


\section{Niacin (vitamin $B_{3}$ or nicotinic acid)}

Niacin in humans comes from exogenous (diet) as well as endogenous sources. The latter is the result of metabolic conversion of tryptophan to niacin. The intestinal absorption of niacin occurs through a specific carrier. Although its molecular identity is not yet established, its kinetic characteristics are similar to that of organic anion transporter 10 (OAT10, encoded by the $S L C 22 A 13$ gene). Niacin deficiency is associated with pellagra, dermatitis, diarrhea and dementia. The main sources of niacin include milk, eggs, meats, fish, and whole grains.

\section{Vitamin $B_{6}$ (pyridoxine, pyridoxal, pyridoxamine)}

Dietary sources of vitamin $\mathrm{B}_{6}$ include meats, fish, potatoes, and fruits. It is also synthesized by resident gut bacteria. The identity of the $\mathrm{B}_{6}$ carrier(s) in vertebrates has not been established. $\mathrm{B}_{6}$ deficiency may be associated with alcoholism, diabetes, celiac and renal diseases, or long-term use of hydrazines or penicillamine. Deficiency of $\mathrm{B}_{6}$ may induce irritability, depression, dermatitis, glossitis, cheilosis, peripheral neuritis, convulsions in infants, and microcytic anemia.

\section{Vitamin $B_{2}$ (riboflavin)}

Dietary sources for $\mathrm{B}_{2}$ include dairy products, eggs, meats, and green leafy vegetables. The intestinal transport of $\mathrm{B}_{2}$ is thought to occur through riboflavin transporters (RFVT1 and RFVT2, encoded by $S L C 52 A 1$ and $S L C 52 A 2$ genes, respectively). Functional $\mathrm{B}_{2}$ deficiency may be associated with inflammatory bowel diseases or chronic alcoholism, while mutations in the SLC52A2 gene have been linked to the Brown-Vialetto-Van Laere syndrome-2. Deficiency in this vitamin is associated with photophobia, cheilosis, glossitis, corneal vascularization, and poor growth.

\section{Vitamin $B_{1}$ (thiamin)}

Thiamin is widely available in dietary sources such as whole grains, nuts, and dried legumes. Intestinal $\mathrm{B}_{1}$ absorption has been attributed to two thiamin transporters in humans (THTR1 and THTR2, encoded by $S L C 19 A 2$ and $S L C 19 A 3$ genes, respectively), which are expressed throughout the GI tract. In addition to rare genetic causes (mutations in the $S L C 19 A 2$ lead to thiamin-responsive megaloblastic anemia and in the SLC19A3 gene - to the thiamin responsive Wernicke's-like encephalopathy), the major causes of dietary thiamin deficiency relate to poor dietary intake and excessive alcohol use.

\section{Fat-Soluble Vitamins}

\section{Vitamin A}

Vitamin A in the diet exists in either retinol or ethyl esters (preformed) or as pro-vitamin A carotenoids. Most of these forms require metabolic conversion. Preformed vitamin A is consumed in the diet in a number of forms such as retinol vitamin $A_{1}$, retinol vitamin $A_{2}$, and retinol esters. Pro-vitamin $A$ has a role in macula pigments and as a precursor for vitamin A. Retinoids have a role in the mammalian life cycle and are important for eye health and immune function. The intestinal absorption of vitamin A depends on its dietary form. Upon ingestion of pro-vitamin A, there is a release of retinol esters. Conversion of 
carotenoids to retinol occurs in the enterocytes. Pro-vitamin A is derived mostly from animal sources such as liver, fish liver oil, dairy products, kidneys, and eggs. Since vitamin A is a fat-soluble vitamin, retinol esters and retinol have to be re-esterified - predominantly by lecithin, acetyltransferase, and with palmitic acid - before incorporation into chylomicrons with other lipids. Chylomicrons then enter the circulation via the lymphatics, followed by apolipoprotein E-dependent internalization by hepatocytes. Hydrolysis and subsequent storage occurs within the hepatic stellate cells, primarily in the form of retinol esters mainly palmitate. Retinol-binding proteins appear to be the major protein responsible for carrying vitamin A from the liver to peripheral tissues. $95 \%$ of retinol in the plasma is bound to the retinol-binding protein, with the remaining $5 \%$ as retinol esters in lipoproteins. Vitamin A deficiency occurs mainly in children due to poor nutrition and/or fat malabsorption and results in xerophthalmia, keratomalacia and irreversible damage to the cornea with night blindness and pigmentary retinopathy. Furthermore, vitamin A deficiency increases mortality from various infections such as measles.

\section{Vitamin D}

Vitamin D usually refers to two major secosteroids - vitamin $\mathrm{D}_{2}$ (ergocalciferol) and vitamin $\mathrm{D}_{3}$ (cholecalciferol). Vitamin $\mathrm{D}_{2}$ is derived from plants and fungi and is added to fortified cow-s milk. Vitamin $\mathrm{D}_{2}$ is present in food as a natural constituent and in many fortified cereals. Other rich sources of vitamin D are fatty fish, including salmon, tuna and mackerel. Vitamin $\mathrm{D}_{3}$ is synthesized in the skin upon UVB (270-300 nm) exposure from 7dihydrocholesterol. The resulting pre-vitamin $\mathrm{D}$ spontaneously isomerizes to cholecalciferol, which is transported by the binding protein into the liver. There, both $\mathrm{D}_{2}$ and $\mathrm{D}_{3}$ undergo 25hydroxylation via CYP27A1, followed by 1a-hydroxylation by CYP27B1 in the kidneys. The most biologically active form of vitamin $\mathrm{D}$ is $1,25(\mathrm{OH})_{2} \mathrm{D}_{3}$ (calcitriol) and, among its many functions, it is involved in the regulation of intestinal absorption of $\mathrm{Ca}^{2+}$ and phosphate $(\mathrm{Pi})$, and their reabsorption in the kidneys. Furthermore, $1,25(\mathrm{OH})_{2} \mathrm{D}_{3}$ acts to mobilize $\mathrm{Ca}^{2+}$ and $\mathrm{Pi}$ from the bones in situations that require maintenance of circulating levels of the two minerals. Therefore, vitamin D is essential in the renal-intestinal-skeletalaxis that maintains bone formation and systemic mineral homeostasis.

The intestinal absorption of vitamin $\mathrm{D}$ is similar to that of vitamin A and occurs by simple passive diffusion in the small intestine. Most of the absorbed vitamin D is taken up by the lymphatics in chylomicrons. The primary impact of a deficiency of vitamin D relates to its effect on $\mathrm{Ca}^{2+}$ and Pi homeostasis. Two conditions related to vitamin $\mathrm{D}$ deficiency include rickets in children and osteomalacia in adults. Vitamin D exerts its transcriptional effects via the vitamin D receptor (VDR) and regulates numerous target genes, such as osteocalcin and RANKL (upregulation), or parathyroid hormone (PTH; downregulation). VDR is highly expressed in intestinal and renal epithelial cells and modulates $\mathrm{Ca}^{2+}$ (re)absorption and bone formation via its action on osteoblasts. VDR is highly expressed in pancreatic beta cells and immune cells.

\section{Vitamin E}

Tocopherol and tocotrienols ( $\alpha, \beta, \Delta$ and $\gamma$ ) of are the two main groups of vitamin $\mathrm{E}$. However, the major biological activity is ascribed to the a-tocopherol which is predominant 
in food - with the exception of soy, which contains high levels of $\gamma$-tocopherol. The major metabolic role of vitamin $\mathrm{E}$ as a lipid-soluble, membrane-bound, and potent antioxidant is to protect the cell from reactive oxygen species produced from lipid oxidation. The common sources of vitamin $\mathrm{E}$ are oil-containing grains and vegetables. Vitamin $\mathrm{E}$ is absorbed passively across the intestinal mucosa, incorporated into micelles, followed by incorporation into chylomicrons, with eventual transfer into the lymphatics. An alternative route for vitamin $\mathrm{E}$ absorption is provided via direct secretion from epithelial cells into the portal venous circulation by HDL efflux. Pancreatic enzymes aid vitamin E absorption and pancreatic insufficiency (i.e. in cystic fibrosis) may lead to vitamin E deficiency. Vitamin E deficiency results in progressive neurological disorders including ataxia, hyperreflexia, repressed vibratory and position sensation, and impairment of balance and coordination.

\section{Vitamin K}

Vitamin K is obtained from leafy vegetables, soybean oil, fruits, seeds, and cow's milk; mostly in the form of phylloquinone (vitamin $\mathrm{K}_{1}$ ). Intestinal bacteria convert vitamin $\mathrm{K}_{1}$ to vitamin $\mathrm{K}_{2}$ (menaquinones) and synthesize $\mathrm{K}_{2}$ de novo. $\mathrm{K}_{2}$ has $60 \%$ of the activity of vitamin $\mathrm{K}_{1}$ and is the main storage form of vitamin $\mathrm{K}$. Newborns are at risk for hemorrhagic disease due to limited placental permeability for vitamin $\mathrm{K}$, low level of vitamin $\mathrm{K}$ in breast milk, and low colonic bacterial synthesis of menaquinones prior to full microbial colonization; thus they require supplementation by injection. Similar to other fat-soluble vitamins, absorption occurs through the lipid pathway in the terminal ileum and is dependent on biliary and pancreatic enzymes. The level of gamma-carboxylated proteins in the blood is the indirect measure of vitamin K status. Deficiency of vitamin K leads to hypoprothrombinemia and hemorrhagic disorders. Deficiency may be related to low dietary intake, small bowel injury and malabsorption, chronic kidney disease, and vitamin D deficiency, aging, or intake of broad-spectrum antibiotics.

\section{Major Minerals (Calcium, Phosphate, Iron, Magnesium) Calcium $\left(\mathrm{Ca}^{2+}\right)$}

Calcium is a major mineral required for a number of structural and physiological mechanisms related to health. The intestine, kidney, bone, and parathyroid glands work together to maintain serum $\mathrm{Ca}^{2+}$ within a narrow range, approx. $2.5 \mathrm{mM}$. The majority of circulating calcium is bound to albumin and the remaining fraction is ionized $\mathrm{Ca}^{2+}$. Major sources of calcium are dairy products, which account for approximately $75 \%$ of dietary calcium intake. The remaining 25 percent comes from cereals, legumes, and vegetables. Dietary lactose has been shown to further enhance calcium absorption. On the other hand, phytic acid and oxalate in vegetables and dietary fiber bind strongly to calcium interfering with its absorption.

The amount of calcium absorbed in the gut depends on its consumption, sojourn time in the various segments of the small and large intestine, and the amount of soluble $\mathrm{Ca}^{2+}$ available for absorption. The latter is mainly determined by the $\mathrm{pH}$ of each segment. Although the colon accounts for only about $7 \%$ of total $\mathrm{Ca}^{2+}$ absorption, it becomes more important in the setting of short bowel syndrome. Calcium absorption occurs via two complementary 
mechanisms [21]. At normal to high dietary calcium intake, the non-saturable, paracellular diffusive pathway predominates. Although passive, it is nevertheless a regulated process; mostly via the dynamics of the epithelial tight junctions. Claudins Cldn-2,Cldn-12, and Cldn-15 facilitate $\mathrm{Ca}^{2+}$ absorption, while Cldn-5 limits it. In the jejunum and ileum, except in the first weeks after birth, $1,25(\mathrm{OH})_{2} \mathrm{D}_{3}$ enhances paracellular $\mathrm{Ca}^{2+}$ permeability. Although the mechanism responsible is not fully defined, it has been suggested that upregulation of Cldn-2 and Cldn-12 and downregulation of Cadherin-17 and Aquaporin-8 may be involved.

The saturable transcellular process occurs at lower luminal calcium levels against a concentration gradient. It predominates in the duodenum and jejunum, is regulated by nutritional and physiological factors (mainly vitamin D) and is driven by TRPV6, and to a lesser extent TRPV5 - non-voltage-gated $\mathrm{Ca}^{2+}$ channels expressed in the apical membranes of the enterocytes. Another L-type channel located in the apical membrane, $\mathrm{Ca}_{\mathrm{v}} 1.3$, is thought to provide another mechanism of active $\mathrm{Ca}^{2+}$ transport under depolarizing conditions such as during digestion, when luminal $\mathrm{Ca}^{2+}$ is in abundance. Once transported across the enterocyte's apical membrane, $\mathrm{Ca}^{2+}$ is bound to calbindin-D9k $(S 100 G)$. This serves two purposes: to buffer $\mathrm{Ca}^{2+}$ and maintain intracellular $\mathrm{Ca}^{2+}$ concentrations below $10^{-7} \mathrm{~mol} / \mathrm{L}$ to prevent epithelial cell apoptosis, and to carry $\mathrm{Ca}^{2+}$ to the BLM. Calcium exits the enterocyte at the BLM by two mechanisms: via $\mathrm{Ca}^{2+}$ ATPase PMCA1b (ca. 80\% contribution), and through the $\mathrm{Na}^{+} / \mathrm{Ca}^{2+}$ exchanger $\mathrm{NCX} 1$ (SLC8A1; ca. $20 \%$ contribution). Expression of each of these carriers is enhanced by vitamin $\mathrm{D}_{3}$.

\section{Phosphate}

Along with $\mathrm{Ca}^{2+}$, phosphate is important for bone formation and energy metabolism. $85 \%$ of phosphate is deposited in the bones and $14 \%$ is in cells, where it is essential for cellular metabolism. Energy for a variety of metabolic processes requires phosphate in the form of creatinine, phosphate, and ATP; thus making phosphate critical for cell physiology and metabolism. Dietary sources of phosphate include dairy products, grains, and meats; which constitute the major sources of dietary phosphate. Phosphate is abundant in nature and reaches an intracellular concentration of 1-2 $\mathrm{mmol} / \mathrm{L}$.

Phosphate absorption occurs primarily in the small intestine and its relative efficiency is greater in the duodenum, followed by the jejunum, and then the ileum [22]. The majority of phosphate is absorbed in the jejunum due to its greater length. It occurs via two processes: $\mathrm{Na}^{+}$- and 1,25-(OH $)_{2} \mathrm{D}_{3}$-dependent co-transport driven by the apical $\mathrm{Na}^{+}$phosphate transporter NaPi-IIb, which belongs to a family of SLC34 solute carriers (SLC34A2); and via the passive diffusion process through the paracellular pathway, which operates during high intake of phosphate. The exit of phosphate across the BLM is likely to occur by facilitated diffusion via unknown phosphate transporters. Type III $\mathrm{Na}^{+}$phosphate transporters PIT1 and PIT2 have also been found at the enterocyte's BLM and they function to transport phosphate into the cell from the serosal site during dietary insufficiency for cellular phosphate metabolism. A number of factors regulate phosphate transport, including age. Rapid phosphate absorption occurs during early life to meet the demands of growth. $1,25-(\mathrm{OH})_{2} \mathrm{D}_{3}$ increases phosphate absorption via action on NaPi-IIb. Estrogens have a 
similar effect, although not directly affecting NaPi-IIb expression and activity. Metabolic acidosis, which leads to phosphaturia, does not alter systemic phosphate levels, likely due to upregulation of intestinal NaPi-IIb-mediated absorption. EGF, glucocorticoids, and FGF23 (the latter through altered vitamin D3 metabolism), all decrease $\mathrm{Na}^{+}$-dependent intestinal phosphate absorption.

\section{Magnesium (Mg)}

Magnesium is the fourth most abundant cation in the body. The human adult contains approximately $25-28 \mathrm{~g}$ of $\mathrm{Mg}^{2+}$ with $60 \%$ of it deposited in the bones. Magnesium is required for a number of cellular functions as a co-factor for a variety of enzymatic reactions, including phosphate group transfer from high-energy nucleotide triphosphates. In humans, $\mathrm{Mg}^{2+}$ is absorbed primarily in the jejunum and ileum, with both passive and active transport processes implicated [21]. Paracellular movement of $\mathrm{Mg}^{2+}$ is driven by both concentration gradient as well as by "solvent drag effect", and also occurs across a much "tighter" colonic epithelium. Transcellular $\mathrm{Mg}^{2+}$ absorption is secondary to facilitated diffusion and to the active transport mediated by the transient potential ion channels TRPM6 and TRPM7, which heterotetramerize and allow $\mathrm{Mg}^{2+}$ to be transported through the apical membrane. $\mathrm{Na}^{+} / \mathrm{Mg}^{2+}$ exchange or $\mathrm{Mg}^{2+}$ ATPase have been postulated but not confirmed in humans.

Iron (Fe)

Iron is an essential mineral required for a number of physiological functions including serving as an oxygen-binder and transporter, cellular respiration, regulation of cell growth and differentiation, electron transfer reactions, and the control of gene expression. It is estimated that humans ingest $20-30 \mathrm{mg}$ of iron per day, however, only $1.5 \mathrm{mg}$ per day is absorbed by adult males. Adult females require additional $1.5-2 \mathrm{mg}$ per day to compensate for losses through menstrual bleeding and fetal requirements during pregnancy. It is estimated that the human body contains $3-5 \mathrm{~g}$ of iron stores, mostly present in hemoglobin or myoglobin.

Iron balance must be tightly controlled via a number of regulatory mechanisms. Since there is no mechanism for excreting iron from the body, its absorption is the main mechanism for controlling the amount of iron present in the body [23]. Most of the iron present in the diet is in the insoluble ferric form $\left(\mathrm{Fe}^{3+}\right) \cdot \mathrm{Fe}^{3+}$ is reduced to its absorbable ferrous $\mathrm{Fe}^{2+}$ form by duodenal brush border cytochrome b reductase 1 (DCYTB; CYBRD1), as well as dietary ascorbic acid. Once in the ferrous state, iron is transported across the brush border membranes via the versatile divalent metal transporter 1 (DMT1), which in addition to iron, is also capable of transporting magnesium, copper, zinc, cobalt, and cadmium. DMT1 is a proton-coupled symporter and is upregulated in the setting of anemia and hypoxia. Iron deficiency regulates DMT1 expression and activity by affecting its mRNA stability though Fe-responsive elements in the $3^{\prime}$-untranslated regions of DMT1 transcript. Heme iron transport in the GI tract occurs via a mechanism different than DMT1, involving a low affinity heme transporter designated HCP1 (SLC46A1). Similar to DMT1, HCP1 is expressed at the brush border membrane and its expression increases in response to hypoxia. $\mathrm{HCP} 1$ also functions as a high-affinity folate transporter. 
The exit of $\mathrm{Fe}$ across the basolateral membrane of the enterocyte occurs through ferroportin (FPN1, SLC4OA1). This process is coupled to $\mathrm{Fe}^{2+}$ oxidation at the BLM in order to enable oxidized iron to bind to transferrin in the interstitial fluid and plasma for body distribution. This function is provided by the basolateral iron oxidase hephaestin $(H E P H)$. Cellular iron export is regulated (reduced) by the liver hepcidin antimicrobial peptide (HAMP), which acts upon FPN1 to reduce iron export from the cells. HAMP is also induced by high Fe body stores and inflammation (via IL-6).

Hereditary hemochromatosis is secondary to mutations in the HFE gene. HFE protein is found in the duodenal crypt cells associated with $\beta-2$ microglobin and transferrin receptors. HFE mutations prevent Fe from being taken into the crypt cells, leading to a relative $\mathrm{Fe}$ deficiency in the duodenal crypt cells. This, in turn, leads to an increase in DMT1 expression and activity, resulting in abnormally high iron absorption. Mutations in FPN1 (SLC4OAI) lead to an autosomal dominant form of hemochromatosis (type 4), also known as ferroportin disease. Rare mutations in DMT1 (SLC11A2) have been reported as responsible for an absorptive defect leading to hypochromic microcytic anemia. Secondary interference with DMT1 function can occur in intestinal disorders like celiac disease, which damages the duodenal villus structure rendering patients unable to absorb iron. Therefore, patients who are Fe-deficient and non-responsive to iron supplementation need to be investigated for celiac disease.

\section{Trace Elements (Micronutrients)}

\section{Zinc (Zn) absorption}

Zinc is an essential nutrient for a number of cellular functions; including cell growth and development, the immune system, taste, and smell; and it is present in various enzymes required for important biological functions. The availability of $\mathrm{Zn}$ in the diet depends on the source of the diet. For example, $\mathrm{Zn}$ availability in red meat is approximately $55 \%$, compared to high fiber cereal at approximately $15 \%$. Zn bioavailability is greater from human milk than cow's milk. The amount of $\mathrm{Zn}$ in the body is approximately $2 \mathrm{~g}$ and it is present in a wide variety of enzymes. Zinc appears to undergo enterohepatic circulation. The absorption of $\mathrm{Zn}$ is impaired by phytate and oxalate in the diet through their chelating properties. The absorption of $\mathrm{Zn}$ occurs throughout the GI tract, including the colon, although the majority is absorbed in the duodenum and proximal jejunum [24]. Homeostasis maintains a constant intracellular $\mathrm{Zn}$ concentration and a plasma concentration within the reference range of 11$25 \mu \mathrm{mol} / \mathrm{L}(0.7-1.6 \mathrm{mg} / \mathrm{L})$. During low dietary $\mathrm{Zn}$ supply, transport is upregulated, enabling the efficiency of absorption to increase to almost $100 \%$. A number of $\mathrm{Zn}$ transport proteins have been described, including the Zip4 (SLC39A4), which appears to be the major apical $\mathrm{Zn}$ transporter in the enterocyte. Indeed, mutations in Zip4 are responsible for the disorder acrodermatitis enertopathica; which results in failure to thrive, skin rashes and diarrhea. Zip5 (SLC39A5) appears to be the basolateral transport protein. Zip11 (SLC39A11) appears to be expressed in parietal cells and may have a role in gastric acid secretion. Zip10, 11 and 14 appear to be responsible for membrane transport in various tissues. The other transporters include ZnT1 (SLC3OAI), which is involved in the basolateral and vesicular transport. $\mathrm{ZnT2}, 4,5,6$, and 7 also contribute to vesicular $\mathrm{Zn}$ transport and in the trans-Golgi network 
membrane. Following transport across the apical membrane through Zip4, the ZnT transport proteins appear to be responsible for vesicular transport inside the enterocyte and then exit through the basolateral membrane via Zip5. Metallothionein (MT) is an intracellular metal binding protein which reacts rapidly to $\mathrm{Zn}$ status. High dietary levels lead to increased intestinal MT synthesis, Zn sequestration, and altered binding capacity. It therefore appears that MT may have a role in both $\mathrm{Zn}$ storage and regulation.

\section{Copper (Cu) absorption}

Copper is an essential nutrient required for a number of metabolic reactions. Compared to other trace elements, relatively little $\mathrm{Cu}$ is stored in the body; with the highest levels in the brain, liver, and kidneys. Copper is found in a number of dietary sources, including fish and green vegetables. The average diet includes 1-3 mg per day. Copper absorption occurs in the stomach and small intestine, primarily the duodenum. Zinc inhibits $\mathrm{Cu}$ absorption, which is why $\mathrm{Zn}$ is utilized in patients with Wilson's disease, a disorder characterized by $\mathrm{Cu}$ accumulation. Copper absorption is a saturable process [25]. The luminal copper is first reduced from cupric $\left(\mathrm{Cu}^{2+}\right)$ state to cuprous $\left(\mathrm{Cu}^{+}\right)$form by cytochrome B reductase 1 (CYPBR1) and the six-transmembrane epithelial antigen of the prostate (STEAP) family proteins. $\mathrm{Cu}^{+}$is then taken up by the apical high-affinity copper transporter 1 (CTR1; SLC31A1). The DMT1 iron transporter may also be able to transport copper, especially during iron deprivation. Due to the high toxicity of free cytosolic copper, it is transferred to the basolateral membrane by a series of intracellular chaperones (e.g. COX17 or ATOX1) which deliver it to ATP7A P-type ATPase present in the trans-Golgi network (for cuproenzyme synthesis) or at the basolateral membrane (for extrusion). Mutations in ATP7A result in Menkes disease, a terminal, progressive, neurological disorder secondary to $\mathrm{Cu}$ accumulation within the enterocytes. ATP7A is different from ATP7B, a Cu transporter in the hepatocytes with mutations responsible for Wilson-s disease.

\section{Manganese (Mn) and Cadmium (Cd) absorption}

Intestinal absorption of Mn and Cd occurs through a DMT1-mediated active transport, as well as by passive diffusion. Zip8 (SLC39A8) and Zip14A/Zip14B (alternative splice variants of the $S L C 39 A 14$ gene) may also be involved in the transport of both metals. The export of Mn from the enterocyte may involve pathways of iron export and binding to transferrin. In the blood, $\mathrm{Mn}$ is primarily distributed by apotransferrin.

\section{Selenium (Se) absorption}

Selenium is an important trace element and is present in the diet mainly as selenomethionine from plants and selenocysteine from animal tissue. In general, Se levels in the soil dictate the amount present in food in a particular region. As an example, Keshan disease (congestive cardiomyopathy) was first described in Keshan County of the Heilongjiang province in China, and is the result of a combination of dietary deficiency of selenium and the presence of a mutated strain of Coxsackievirus. Selenium-enriched yeast provides a very good source used for food fortification. The transport of Se in the enterocyte appears to be a saturable process. Recent evidence suggests that the amino acid transporters SLC3A1 and SLC1A4 might be involved in Se transport, and is it is likely that the transcellular movement of Se is 
similar to amino acid transport, including utilization of the basolateral amino acid transporters.

\section{Chromium (Cr) absorption}

Chromium is widely available in foods. Absorption of $\mathrm{Cr}$ first involves $\mathrm{Cr}$ being changed to the trivalent $\mathrm{Cr}^{3+}$ state. $\mathrm{Cr}^{3+}$ is solubilized and complexed with ligands in the stomach prior to absorption throughout the small intestine, especially in the jejunum. It is believed that $\mathrm{Cr}$ absorption uses some of the pathways utilized by the iron absorption mechanism. Chromium deficiency has been associated with development of glucose intolerance.

\section{Acknowledgments}

We thank Mrs. Vera Madril and Mrs. Trudy Meckler for their editorial assistance.

\section{References}

[1]. Kiela, PR.; Ghishan, FK. Na+-H+ exchange in mammalian digestive tract. In: Johnson, LR., editor. Physiology of the gastrointestinal tract. Academic Press; 2012. p. 1781-818.

[2]. Cuppoletti, J.; Malinowska, DH. Ion channels of the epithelia of the gastrointestinal tract. In: Johnson, LR., editor. Physiology of the gastrointestinal tract. Academic Press; 2012. p. 1863-76.

[3]. Xu H, Chen R, Ghishan FK. Subcloning, localization, and expression of the rat intestinal sodiumhydrogen exchanger isoform 8. Am J Physiol Gastrointest Liver Physiol. 2005; 289:G36-41. [PubMed: 15731506]

[4]. Collins JF, Xu H, Kiela PR, Zeng J, Ghishan FK. Functional and molecular characterization of NHE3 expression during ontogeny in rat jejunal epithelium. Am J Physiol. 1997; 273:C1937-46. [PubMed: 9435499]

[5]. Collins JF, Honda T, Knobel S, Bulus NM, Conary J, DuBois R, et al. Molecular cloning, sequencing, tissue distribution, and functional expression of a $\mathrm{Na}+\mathrm{H}+$ exchanger (NHE-2). Proc Natl Acad Sci U S A. 1993; 90:3938-42. [PubMed: 7683411]

[6]. Janecke AR, Heinz-Erian P, Yin J, Petersen BS, Franke A, Lechner S, et al. Reduced sodium/ proton exchanger NHE3 activity causes congenital sodium diarrhea. Hum Mol Genet. 2015; 24(23):6614-23. [PubMed: 26358773]

[7]. Spencer AG, Labonte ED, Rosenbaum DP, Plato CF, Carreras CW, Leadbetter MR, et al. Intestinal inhibition of the $\mathrm{Na}+\mathrm{H}+$ exchanger 3 prevents cardiorenal damage in rats and inhibits $\mathrm{Na}+$ uptake in humans. Sci Transl Med. 2014; 6:227ra36.

[8]. Hoglund P, Haila S, Socha J, Tomaszewski L, Saarialho-Kere U, Karjalainen-Lindsberg ML, et al. Mutations of the Down-regulated in adenoma (DRA) gene cause congenital chloride diarrhoea. Nat Genet. 1996; 14:316-9. [PubMed: 8896562]

[9]. Alper SL, Sharma AK. The SLC26 gene family of anion transporters and channels. Mol Aspects Med. 2013; 34:494-515. [PubMed: 23506885]

[10]. Romero MF, Chen AP, Parker MD, Boron WF. The SLC4 family of bicarbonate $(\mathrm{HCO}(3)(-))$ transporters. Mol Aspects Med. 2013; 34:159-82. [PubMed: 23506864]

[11]. Astbury SM, Corfe BM. Uptake and metabolism of the short-chain fatty acid butyrate, a critical review of the literature. Curr Drug Metab. 2012; 13:815-21. [PubMed: 22571479]

[12]. Hadjiagapiou C, Schmidt L, Dudeja PK, Layden TJ, Ramaswamy K. Mechanism(s) of butyrate transport in Caco-2 cells: role of monocarboxylate transporter 1. Am J Physiol Gastrointest Liver Physiol. 2000; 279:G775-80. [PubMed: 11005765]

[13]. Tamai I, Takanaga H, Maeda H, Sai Y, Ogihara T, Higashida H, et al. Participation of a protoncotransporter, MCT1, in the intestinal transport of monocarboxylic acids. Biochem Biophys Res Commun. 1995; 214:482-9. [PubMed: 7677755]

[14]. Markovich D. Slc13a1 and Slc26a1 KO models reveal physiological roles of anion transporters. Physiology (Bethesda). 2012; 27:7-14. [PubMed: 22311966] 
[15]. Hatch M, Freel RW. Intestinal transport of an obdurate anion: oxalate. Urol Res. 2005; 33:1-16. [PubMed: 15565438]

[16]. Wright, EM.; Sala-Rabanal, M.; Loo, DDF.; Hirayama, BA. Sugar absorption. In: Johnson, LR., editor. Physiology of the gastrointestinal tract. Academic Press; 2012. p. 1583-94.

[17]. Hirschhorn N, Kinzie JL, Sachar DB, Northrup RS, Taylor JO, Ahmad SZ, et al. Decrease in net stool output in cholera during intestinal perfusion with glucose-containing solutions. N. Engl J Med. 1968; 279:176-81. [PubMed: 4968807]

[18]. Carpenter CC. The erratic evolution of cholera therapy: from folklore to science. Clin Ther. 1990; 12(Suppl. A):22-7. discussion 8. [PubMed: 2187609]

[19]. Burant CF, Takeda J, Brot-Laroche E, Bell GI, Davidson NO. Fructose transporter in human spermatozoa and small intestine is GLUT5. J Biol Chem. 1992; 267:14523-6. [PubMed: 1634504]

[20]. Said, HM.; Verkman, AS. Mechanisms and regulation of intestinal absorption of water-soluble vitamins: cellular and molecular aspects. In: Johnson, LR., editor. Physiology of the gastrointestinal tract. Academic Press; 2012. p. 1711-56.

[21]. van de Graaf SF, Bindels RJ, Hoenderop JG. Physiology of epithelial Ca2+ and Mg2+ transport. Rev Physiol Biochem Pharmacol. 2007; 158:77-160. [PubMed: 17729442]

[22]. Kiela PR, Ghishan FK. Recent advances in the renal-skeletal-gut axis that controls phosphate homeostasis. Lab Invest. 2009; 89:7-14. [PubMed: 19029978]

[23]. Gulec S, Anderson GJ, Collins JF. Mechanistic and regulatory aspects of intestinal iron absorption. Am J Physiol Gastrointest Liver Physiol. 2014; 307:G397-409. [PubMed: 24994858]

[24]. Livingstone C. Zinc: physiology, deficiency, and parenteral nutrition. Nutr Clin Pract. 2015; 30:371-82. [PubMed: 25681484]

[25]. van den Berghe PV, Klomp LW. New developments in the regulation of intestinal copper absorption. Nutr Rev. 2009; 67:658-72. [PubMed: 19906252] 


\section{Practice points}

- A clinical understanding of the transport of nutrients across the gastrointestinal tract allows us to enhance the management of malabsorption syndromes.

- $\quad$ The manifestations of alterations of these transport proteins results in malabsorption.

- The laboratory investigations involved testing the stools for the presence of malabsorbed nutrients and electrolytes supplemented by invasive tests, including defining mutations of transport proteins, resulting in a diseased state. 


\section{Research agenda}

Research on understanding the functional properties of the GI tract based on:

- $\quad$ Further advances in the area of molecular cloning of transport proteins involved in the absorption of nutrients.

- $\quad$ Further advances in the area of gene regulation. 


\section{Table 1}

Intestinal Amino acid transport systems.

\begin{tabular}{|c|c|}
\hline System & Details \\
\hline $\mathrm{B}^{0}$ & $\begin{array}{l}\text { - } \mathrm{Na}^{+} \text {dependent transport of neutral L-amino acids (with amino group at a position). } \\
\text { - Gene: SLC6A19Protein: } \mathrm{B}^{0} \mathrm{AT} 1\end{array}$ \\
\hline $\mathrm{B}^{0,+}$ & $\begin{array}{l}-\mathrm{Na}^{+} \text {and } \mathrm{Cl}^{-} \text {dependent transport of neutral and cationic L-amino acids, and certain neutral D-amino acids. } \\
\text { - Gene: } S L C 6 A 14 \text { Protein: } \mathrm{ATB}^{0+}\end{array}$ \\
\hline$b^{0,+}$ & $\begin{array}{l}\text { - } \mathrm{Na}^{+} \text {independent transport of neutral and cationic L-amino acids, and cystine. } \\
\text { - Genes: } S L C 7 A 9 \& S L C 3 A 1 \text { Protein: Heterodimer of } \mathrm{b}^{0+} \mathrm{AT} \text { and } \mathrm{rBAT}\end{array}$ \\
\hline IMINO & $\begin{array}{l}\text { - } \mathrm{Na}^{+} \text {and } \mathrm{Cl}^{-} \text {dependent transport of imino acids such as proline, hydroxyproline, and pipecolic acid. } \\
\text { - Gene: SLC6A20 Protein: SIT1 }\end{array}$ \\
\hline$\beta$ & $\begin{array}{l}-\mathrm{Na}^{+} \text {and } \mathrm{Cl}^{-} \text {dependent transport of taurine and } \beta \text {-alanine. } \\
\text { - Gene: } S L C 6 \text { 6 } 6 \text { Protein: TAUT }\end{array}$ \\
\hline $\mathrm{X}^{-}{ }_{\mathrm{AG}}$ & $\begin{array}{l}\text { - } \mathrm{Na}^{+} \text {and } \mathrm{H}^{+} \text {dependent transport of anionic amino acid such as aspartate and glutamate, driven by } \mathrm{K}^{+} \text {efflux. } \\
\text { - Gene: } S L C 1 A 1 \text { Protein: EAAC1 }\end{array}$ \\
\hline ASC & $\begin{array}{l}\text { - } \mathrm{Na}^{+} \text {dependent obligatory neutral L-amino acid exchanger with specificity similar to system } \mathrm{B}^{0} \text {, with preference for alanine, serine, } \\
\text { and cysteine. } \\
\text { - Gene: } S L C 1 A 5 \text { Protein: ASCT2 }\end{array}$ \\
\hline $\mathrm{N}$ & $\begin{array}{l}\text { - } \mathrm{Na}^{+} \text {coupled transport of glutamine, asparagine and histidine in exchange for intracellular } \mathrm{H}^{+} \text {. Present predominantly in intestinal } \\
\text { crypts. } \\
\text { - Genes: } S L C 38 A 3 \text { and } S L C 38 A 5 \text { Proteins: SN1 and SN2 } \\
\text { - SN2 is predominantly responsible for the uptake of glutamine across the brush border membrane of intestinal crypt cells. }\end{array}$ \\
\hline PAT & $\begin{array}{l}-\mathrm{H}^{+} \text {coupled electrogenic transport of short chain amino acids such as glycine, alanine and proline. } \\
\text { - Gene: SLC36A1 Protein: PAT1 }\end{array}$ \\
\hline
\end{tabular}

Best Pract Res Clin Gastroenterol. Author manuscript; available in PMC 2017 April 01. 